This is the peer reviewed version of the following article: Muller, I., Pinchera, A., Fiore, E. et al. J Endocrinol Invest (2011) 34: 349. https://doi.org/10.1007/BF03347458

The final publication is available at $\mathrm{https}$ ///ink.springer.com/article/10.1007/BF03347458

\title{
High prevalence of Breast Cancer in patients with Benign Thyroid Diseases
}

Ilaria Muller, Aldo Pinchera, Emilio Fiore, Valentina Belardi, Veronica Rosellini, Elisa Giustarini and Claudio Giani

Department of Endocrinology, University of Pisa, Italy

Running title: Breast Cancer and Thyroid Disease

Key words: breast cancer, benign thyroid disease, thyroid autoimmunity, nodular goiter.

Corresponding author.

Ilaria Muller

Department of Endocrinology, University of Pisa

Via Paradisa 2, 56100 Pisa, Italy

e-mail: ilaria.muller@hotmail.it

Tel: 0039-050-995001

Fax: 0039-050-578772 
This is the peer reviewed version of the following article: Muller, I., Pinchera, A., Fiore, E. et al. J Endocrinol Invest (2011) 34: 349. https://doi.org/10.1007/BF03347458

The final publication is available at $\mathrm{https}$ ///ink.springer.com/article/10.1007/BF03347458

\section{Abstract}

Background: in patients with breast cancer (BC) a high prevalence of benign thyroid diseases (BTD) has been described, Hashimoto's thyroiditis accounting for a large extent for this association. The aim of this study was to evaluate the prevalence of $\mathrm{BC}$ in a large group of patients with BTD.

Patients: clinical records of 622 consecutive patients with BTD were examined. BC prevalence in BTD patients was compared with BC frequency in general population living in the same country.

Results: BC prevalence in patients with BTD $(38 / 622 ; 6.11 \%)$ was significantly higher $(\mathrm{p}=0.0002)$ with respect to BC frequency in general population (2.07\%). When patients were divided according to the age of menopause, in females older than 49 years BC frequency in BTD was significantly higher than in age-matched population $(7.6 \%$ vs $3.3 \%$; $\mathrm{p}=$ 0.006), while in female aged 30-49 years BC frequency in BTD was higher but not statistically significant than in agematched population $(3.7 \%$ vs $0.5 \% ; \mathrm{p}=0.06)$. No significant difference of BC prevalence was found when patients were grouped according to the diagnosis of thyroid disorders: Graves' Disease, Hashimoto's Thyroiditis, Nodular Goiter associated or not associated with serum thyroid autoantibodies (TAb). No significant difference of BC frequency was observed between $\mathrm{TAb}+(26 / 377 ; 6.9 \%)$ and $\mathrm{TAb}-(12 / 245 ; 4.9 \%)$ patients. The distribution of known risk factors for breast malignancies was similar in patients with or without BC.

Conclusion: in patients with BTD the prevalence of BC is significantly higher than the expected, showing the usefulness of screening for breast malignancy of patients with BTD. 
This is the peer reviewed version of the following article: Muller, I., Pinchera, A., Fiore, E. et al. J Endocrinol Invest (2011) 34: 349. https://doi.org/10.1007/BF03347458

The final publication is available at $\mathrm{https}$ ://ink.springer.com/article/10.1007/BF03347458

\section{INTRODUCTION}

The relationship between breast cancer $(\mathrm{BC})$ and thyroid diseases has been widely reported in literature (1-7). In particular a high frequency of autoimmune thyroid disorders has been reported in BC patients and Hashimoto's thyroiditis accounts for a large extent for this association (8-11). A high incidence of serum anti thyro-peroxidase antibodies (TPOAb, marker of autoimmune thyroid disease) was detected both in treated (12) and untreated (13) BC patients and recently Fiore et al. (14) have demonstrated a positive predictive role of TPOAb in a group of patients with high malignant BC disease. Besides, Garner et al (15) have found an increased prevalence of BC in a large group of patients with thyroid malignancy. This observation has been previously reported by other studies $(1,7,16,17)$, confirming the association between these two malignancies.

Even if an increased frequency of thyroid disorders in patients with BC has been extensively reported, few data are available on BC frequency in patients with benign thyroid diseases (BTD). In particular Weiss (18) and Simon (19) did not found an association between BTD and BC, while Moseson (20) reported an increased frequency of BC in patients treated for hyperthyroidism. However, these works were based only on patients interviews and the criteria used for BTD diagnosis were not specified.

Aim of this study was to evaluate the prevalence of $\mathrm{BC}$ in a large group of patients with autoimmune and non autoimmune BTD, using well defined diagnostic criteria. The results were compared with the frequency of BC observed in general population living in the same country. In BTD patients we also evaluated the relevance of the most important risk factors for breast malignancies such as family history, age of menarche or menopause, number/age of pregnancies, previous or concomitant estrogens administration and obesity. We found that in patients with BTD the frequency of BC is significantly higher with respect to the prevalence of $\mathrm{BC}$ in general female population. 
This is the peer reviewed version of the following article: Muller, I., Pinchera, A., Fiore, E. et al. J Endocrinol Invest (2011) 34: 349. https://doi.org/10.1007/BF03347458

The final publication is available at https://link.springer.com/article/10.1007/BF03347458

\section{PATIENTS AND METHODS}

\section{Patients}

We studied the prevalence of BC in a large group of patients with BTD. Clinical records of 622 consecutive female patients with BTD were examined. Patients were not submitted to any specific diagnostic procedure for BC apart for the standard screening employed in Italian population.

We selected patients aged over than 29 years (mean age: $54.3 \pm 9.9$ years, range $30-84$ years), followed at the Department of Endocrinology, University of Pisa, Italy, since 1995, (mean follow-up: $7.2 \pm 3.7$ years). In all cases the diagnosis of BC was confirmed by histology.

The prevalence of $\mathrm{BC}$ in $\mathrm{BTD}$ patients was compared to the frequency of $\mathrm{BC}$ in general population living in the same country (data obtained from the Italian National Institute of Cancer - Istituto Nazionale Tumori, Milano) in 2005 (21).

\section{Methods}

All subjects were submitted to clinical and ultrasound thyroid evaluation. Blood samples were drawn for determination of serum free thyroid hormones (FT4 and FT3), thyroid stimulating hormone (TSH), thyroglobulin antibodies (TgAb), and thyroperoxidase antibodies (TPOAb). FT4 and FT3 were measured by radio-immune assay (RIA) (FT4 by Liso Phase kit - normal range 7-17 pg/ml; FT3 by Liso-Phase kit - normal range 2.7-5.7 pg/ml; Technogenetics, s.r.1., Milan, Italy). TSH was measured by a sensitive immunoradiometric assay (Delphia Pharmacia, Turku, Finland - normal range $0.4-3.4 \mu \mathrm{U} / \mathrm{ml}$ ). TgAb and TPOAb were measured by an immunoenzymatic assay (AIA-Pack TgAb, and TPOAb, Tosoh, Tokyo, Japan) and expressed as U/mL. Subjects with values of $\mathrm{TgAb}$ greater than $30 \mathrm{U} / \mathrm{mL}$ and values of TPOAb greater than $10 \mathrm{U} / \mathrm{mL}$ were considered positive for thyroid auto-antibodies (TAb). Ultrasound evaluation of the thyroid gland was carried out using a commercially available realtime instrument (Aloka SSD 121, Aloka Co., Tokyo, Japan) using a 7.5-megahertz (MHz) linear transducer. Thyroid volume was calculated according to the formula of the ellipsoid model (22); $12 \mathrm{~mL}$ was considered the upper limit for normal thyroid volume in adult females. The presence of thyroid nodules, solid or mixed, and thyroid cysts was recorded if they were greater than 10.0 mm. The echodensity of the thyroid was also examined, and the level of echogenicity was evaluated according to the method of Marcocci et al. (23). Thyroid scintiscan was performed in all patients with thyroid nodular diseases. Fine needle aspiration for cytology was performed in all cold nodular lesions. Patients with documented thyroid carcinoma were excluded.

\section{Diagnostic criteria for BTD}


This is the peer reviewed version of the following article: Muller, I., Pinchera, A., Fiore, E. et al. J Endocrinol Invest (2011) 34: 349. https://doi.org/10.1007/BF03347458

The final publication is available at https://link.springer.com/article/10.1007/BF03347458

The diagnosis of thyroid disease was performed according to clinical, hormonal and instrumental parameters, including fine needle aspiration. The diagnosis of autoimmune thyroiditis (AT), associated or not with goiter, was based on presence of $\mathrm{TgAb}$ and TPOAb and hypoechoic pattern of thyroid gland at ultrasound examination. The diagnosis of Graves' disease (GD) was established by the presence of diffuse goiter and thyrotoxicosis associated or not with infiltrative ophtalmopathy. Diagnosis was confirmed by the presence of serum anti-TSH-Receptor antibodies (TRAb) (TRAK, BRAHMS, Berlin, Germany; normal range $<1.5 \mathrm{U} / \mathrm{L}$ ). Nodular goiter (NG) was defined as a goiter with one or multiple nodules with no signs of thyroid autoimmunity. Nodular goiter was classified as NGAb+ when associated with the presence of serum $\mathrm{TgAb}$ and/or TPOAb and no hypoechoic pattern of thyroid gland at ultrasound examination.

\section{BTD Distribution}

GD was found in 184/622 (29.6\%), AT in 148/622 (23.8\%), NG in 245/622 (39.4\%) and NGAb+ in 45/622 (7.2\%). Out of 622 patients, $523(84.0 \%)$ had normal FT4, FT3 and TSH levels at the moment of the study. In particular, at the end of follow-up, 99/523 (19.0\%) patients were euthyroid with no therapy, 17/523 (3.2\%) had hyperthyroidism corrected with methimazole and 407/523 (77.8\%) had hypothyroidism corrected with L-thyroxine. In this last group $124 / 407(30.5 \%)$ patients had autoimmune thyroiditis and 283/407 (69.5\%) patients became hypothyroid after radioiodine therapy or thyroidectomy for control of hyperthyroidism or for surgical treatment of large nodular goiter. 99/622 (16.0\%) had nodular goiter under L-thyroxine therapy (80 of NG and 19 of NGAb+ groups respectively).

\section{Statistical analysis}

Data were analyzed by $\chi^{2}$ test. Results were considered statistically significant when $\mathrm{p}$ was $<0.05$. 
This is the peer reviewed version of the following article: Muller, I., Pinchera, A., Fiore, E. et al. J Endocrinol Invest (2011) 34: 349. https://doi.org/10.1007/BF03347458

The final publication is available at https://link.springer.com/article/10.1007/BF03347458

\section{RESULTS}

\section{Prevalence of $B C$ in patients with $B T D$}

BC was detected in 38/622 (6.11\%) patients with BTD. The histological diagnosis was infiltrating ductal carcinoma in $33 / 38(86.8 \%)$ patients and invasive lobular carcinoma in 5/38 (13.2\%) patients. In $27 / 38(71 \%)$ patients BC was detected after the diagnosis of BTD (range: 1-26 years) and in 11/38 (29\%) patients BC was detected before the diagnosis of BTD (range: 1-28 years). According to the prevalence of BC in Italian females aged more than 29 years $(2.07 \%)$, the expected frequency of BC in the group of patients studied should have been 12/622, significantly lower (Figure 1A) than that detected in patients with BTD $\left(38 / 622 ; 6.11 \% ; \chi^{2}\right.$ test $p$ value $\left.=0.0002\right)$.

The mean age of menopause of the study group was $48.5 \pm 4.7$ years and this age was similar in patients with and with no $B C,(47.7 \pm 5.5$ years vs $48.6 \pm 4.6$ years: $p=n s)$.

When patients were divided in two groups according to the mean age of menopause, in female aged 30-49 years, the prevalence of $\mathrm{BC}$ was $9 / 241(3.7 \%)$, while according to the prevalence of $\mathrm{BC}$ in general age-matched population $(0.52 \%)$ the expected frequency should have been lower even if not statistically significant $(2 / 241$, Fisher exact test $p$ value $=0.06)$. In females older than 49 years, BC was found in 29/381 (7.6\%) patients, while according to the prevalence of $\mathrm{BC}$ in general age-matched population $(3.27 \%)$ the expected frequency should have been significantly lower $\left(12 / 381, \chi^{2}\right.$ test $p$ value $\left.=0.006\right)$.

Table 1 summarizes the clinical findings and thyroid therapies in the 38 patients with BC. $14 / 38(36.8 \%)$ patients were euthyroid with no treatment, $4 / 38$ (10.5\%) had nodular goiter under L-thyroxine suppressive therapy (3 of NG and 1 of $\mathrm{NGAb}+$ groups respectively), 2/38 (5.3\%) had hyperthyroidism corrected with methimazole treatment, 2/38 (5.3\%) patients had autoimmune thyroiditis with hypothyroidism corrected with L-thyroxine, 16/38 (42.1\%) patients presented hypothyroidism corrected with L-thyroxine after radioiodine (I-131) therapy or thyroidectomy for control of hyperthyroidism or for surgical treatment of large nodular goiter.

BC was diagnosed in 13/184 (7.1\%) GD, 10/148 (6.8\%) AT, 12/245 (4.9\%) NG and 3/45 (6.7\%) NGAb+. No difference was found between these 4 BTD groups. Patients were also grouped according to the presence $(\mathrm{TAb}+)$ or the absence (TAb-) of anti-thyroid antibodies. The overall prevalence of $\mathrm{TAb}+$ was $377 / 622(60.6 \%)$ patients. The frequency of BC was not significant different between TAb+ $(26 / 377 ; 6.9 \%)$ and TAb- patients $(12 / 245 ; 4.9 \%)$.

We analyzed the possible relationship between BC and I-131 treatment for hyperthyroidism. The frequency of BC in patients treated with I-131 therapy $(11 / 172 ; 6.4 \%)$ was not significantly different to that detected in patients not treated with I-131 therapy $(27 / 450 ; 6.0 \%)$. In particular BC was detected before I-131 treatment in 4/11 (36.4\%) patients (range: 5-23 years) and after I-131 treatment in 7/11 (63.6\%) patients (range: 4-17 years). 
This is the peer reviewed version of the following article: Muller, I., Pinchera, A., Fiore, E. et al. J Endocrinol Invest (2011) 34: 349. https://doi.org/10.1007/BF03347458

The final publication is available at https://link.springer.com/article/10.1007/BF03347458

Risk factors for BC in patients with BTD

As indicated in Table 2, the distribution of known risk factors for breast malignancy was similar in patients with or without BC. 
This is the peer reviewed version of the following article: Muller, I., Pinchera, A., Fiore, E. et al. J Endocrinol Invest (2011) 34: 349. https://doi.org/10.1007/BF03347458

The final publication is available at https://link.springer.com/article/10.1007/BF03347458

\section{DISCUSSION}

Several studies have already provided evidence of a high prevalence of thyroid diseases in patients with BC (1-7, 15). In particular a high frequency of autoimmune thyroid disorders has been reported in BC patients (8-11) and an elevated incidence of serum TPOAb has been detected both in treated (12) and untreated (13) BC patients. Even if an increased frequency of thyroid disorders in patients with $\mathrm{BC}$ has been widely reported, few data are available on the frequency of BC in patients with BTD. In particular Weiss (18) and Simon (19) did not found an association between BTD and BC, while Moseson (20) reported an increased frequency of BC in patients treated for hyperthyroidism. It is important to point out that these works were based only on interviews of patients. Aim of this study was to evaluate the prevalence of BC in a large group of patients with autoimmune and non autoimmune BTD, using well defined diagnostic criteria, including evaluation of free thyroid hormones and TSH, thyroid ultrasound and scintiscan and cytological diagnosis of cold thyroid nodules. We examined the clinical records of 622 consecutive patients with BTD followed-up for $7.2 \pm 3.7$ years and results were compared with frequency of BC detected in general population living in the same country. Our data show that the overall prevalence of BC in patients with BTD is significantly higher than the expected frequency in Italian female population. Besides, we have also found an increased frequency of BC in older patients with BTD, reflecting the age-dependent increase of prevalence of $\mathrm{BC}$ in general population. The cause of the association between thyroid diseases and $\mathrm{BC}$ is not clear, but it is logical to consider that common genetic, endocrine or environmental risk factors may be involved. Iodine may play a role in this association. Actually, iodine deficiency has been shown to be involved both in thyroid and breast diseases. Iodine is essential for the synthesis of thyroid hormones and its deficiency is responsible for endemic goiter (24). It is well known that the BC cells and lactating breast tissues are able to express sodium-iodide symporter (NIS) and iodide uptake is observed in approximately $80 \%$ of BC, but not in normal breast tissue (25). Recently it has also been reported that iodine may modify gene expression in MCF-7 BC cell lines (26). However, even if iodine is involved in the pathogenesis of both thyroid and breast diseases, further studies are needed to clarify its possible role in breast malignancy. It is also possible to hypothesized that estrogens may be involved both in breast tumorigenesis and growth of thyroid gland. Actually ERs are detected in a large part of BC and their interaction with estrogens is involved in the proliferation of neoplastic cells. Besides ER has been found both in normal and pathological thyroid tissues $(27,28)$ and it has been demonstrated that estrogens are involved in proliferation of thyroid cancer cells $(29,30)$.

In our series, no significant difference of BC frequency was observed when patients were grouped according to the diagnosis of thyroid disease. In particular no significant difference was observed between patients with detectable or undetectable TAb: $\mathrm{BC}$ was present in $6.9 \%$ of $\mathrm{TAb}$ positive patients and $4.9 \%$ of $\mathrm{TAb}$ negative patients. This result is 
This is the peer reviewed version of the following article: Muller, I., Pinchera, A., Fiore, E. et al. J Endocrinol Invest (2011) 34: 349. https://doi.org/10.1007/BF03347458

The final publication is available at https://link.springer.com/article/10.1007/BF03347458

apparently in contrast with the increased frequency of TAb in BC patients that has already been reported (12, 13). However, it's important to point out that the prevalence of TAb in our group of patients was $377 / 622(60 \%)$, significantly higher than the frequency of TAb in patients with no thyroid diseases and the high frequency of TAb in our study group could mask the association of $\mathrm{TAb}$ and $\mathrm{BC}$.

The frequency of known risk factors for breast malignancy (table 2) was not significant different in patients with or without BC. It is important to underscore that the role of these factors has been defined in epidemiological studies involving a large number of patients and that the relatively small size of our sample of BTD patients may not allow to draw significant conclusions. However, our results show that in our series of patients with BTD the known risk factors for breast malignancy are equally distributed between females with or without BC. This observation suggests that no selection bias for known $\mathrm{BC}$ risk factors are present in our study group.

A possible relationship between I-131 treatment for hyperthyroidism and development of BC has recently been reported (31), while previous studies did not show this association $(32,33)$. Our results showed that the prevalence of $\mathrm{BC}$ was not significantly different in BTD patients treated $(6.4 \%)$ or not treated $(6.0 \%)$ with I-131. This result suggests that patients with thyroid disease have an increased prevalence of $\mathrm{BC}$ that may not be related to I-131 treatment. However, because of the small number of patients, further studies are needed to clarify the possible association between I-131 treatment and $\mathrm{BC}$.

In conclusion we have shown a significant increase of BC prevalence in patients with BTD. These data are in agreement with previous studies that showed an association between breast and thyroid malignancies and between $\mathrm{BC}$ and thyroid autoimmunity. The relationship between breast and thyroid diseases may have an important clinical relevance and further studies will be needed to shed more light on this point. 
This is the peer reviewed version of the following article: Muller, I., Pinchera, A., Fiore, E. et al. J Endocrinol Invest (2011) 34: 349. https://doi.org/10.1007/BF03347458

The final publication is available at https://link.springer.com/article/10.1007/BF03347458

\section{Declarations of interest and funding}

The authors declare that there is no conflict of interest that could be perceived as prejudicing the impartiality of the research reported.

This research did not received any specific grant from any funding agency in the public, commercial or not-for-profit sector. 
This is the peer reviewed version of the following article: Muller, I., Pinchera, A., Fiore, E. et al. J Endocrinol Invest (2011) 34: 349. https://doi.org/10.1007/BF03347458

The final publication is available at $\mathrm{https}$ ://link.springer.com/article/10.1007/BF03347458

\section{Bibliography}

1. Chalstrey LJ, Benjamin B. High incidence of breast cancer in thyroid cancer patients. Br J Cancer 1966, 20: 670-675

2. Myhill J, Reeve TS, Hales IB. Thyroid function in breast cancer. Acta Endocrinol (Copenh) 1966, 51: 290-300

3. Sicher K, Waterhouse JA. Thyroid activity in relation to prognosis in mammary cancer. Br J Cancer 1967, 21: $512-518$

4. Goldman MB. Thyroid diseases and breast cancer. Epidemiol Rev 1990, 12: 16-28

5. Goldman MB, Monson RR, Maloof F. Cancer mortality in women with thyroid disease. Cancer Res 1990, 50: 2283-2289

6. Smyth PP. Thyroid disease and breast cancer. J Endocrinol Invest 1993, 16: 396-401

7. Turken O, NarIn Y, DemIrbas S, et al. Breast cancer in association with thyroid disorders. Breast Cancer Res 2003, 5: R110-113

8. Mittra I, Perrin J, Kumaoka S. Thyroid and other autoantibodies in British and Japanese women: an epidemiological study of breast cancer. Br Med J 1976, 1: 257-259

9. Ito K, Maruchi N. Breast cancer in patients with Hashimoto's thyroiditis. Lancet 1975, 2: 1119-1121

10. Rasmusson B, Feldt-Rasmussen U, Hegedus L, Perrild H, Bech K, Hoier-Madsen M. Thyroid function in patients with breast cancer. Eur J Cancer Clin Oncol 1987, 23: 553-556

11. Maruchi N, Annegers JF, Kurland LT. Hashimoto's thyroiditis and breast cancer. Mayo Clin Proc 1976, 51: 263-265

12. Giani C, Fierabracci P, Bonacci R, et al. Relationship between breast cancer and thyroid disease: relevance of autoimmune thyroid disorders in breast malignancy. J Clin Endocrinol Metab 1996, 81: 990-994

13. Giustarini E, Pinchera A, Fierabracci P, et al. Thyroid autoimmunity in patients with malignant and benign breast diseases before surgery. Eur J Endocrinol 2006, 154: 645-649

14. Fiore E, Giustarini E, Mammoli C, et al. Favorable predictive value of thyroid autoimmunity in high aggressive breast cancer. J Endocrinol Invest 2007, 30: 734-738

15. Garner CN, Ganetzky R, Brainard J, et al. Increased prevalence of breast cancer among patients with thyroid and parathyroid disease. Surgery 2007, 142: 806-813

16. Sioka C, Fotopoulos A. Association of thyroid cancer with breast cancer. Surgery 2009, 145: 123-124

17. Agarwal DP, Soni TP, Sharma OP, Sharma S. Synchronous malignancies of breast and thyroid gland: a case report and review of literature. J Cancer Res Ther 2007, 3: 172-173

18. Weiss HA, Brinton LA, Potischman NA, et al. Breast cancer risk in young women and history of selected medical conditions. Int J Epidemiol 1999, 28: 816-823

19. Simon MS, Tang MT, Bernstein L, et al. Do thyroid disorders increase the risk of breast cancer? Cancer Epidemiol Biomarkers Prev 2002, 11: 1574-1578

20. Moseson M, Koenig KL, Shore RE, Pasternack BS. The influence of medical conditions associated with hormones on the risk of breast cancer. Int J Epidemiol 1993, 22: 1000-1009

21. De Angelis R, Grande E, Inghelmann R, et al. Cancer prevalence estimates in Italy from 1970 to 2010 . Tumori 2007, 93: 392-397

22. Rago T, Chiovato L, Grasso L, Pinchera A, Vitti P. Thyroid ultrasonography as a tool for detecting thyroid autoimmune diseases and predicting thyroid dsfunction in apparently healthy subjects. J Endocrinol Invest 2001, 24: 763-769

23. Marcocci C, Vitti P, Cetani F, Catalano F, Concetti R, Pinchera A. Thyroid ultrasonography helps to identify patients with diffuse lymphocytic thyroiditis who are prone to develop hypothyroidism. J Clin Endocrinol Metab 1991, 72: 209-213

24. Aghini-Lombardi F, Antonangeli L, Martino E, et al. The spectrum of thyroid disorders in an iodine-deficient community: the Pescopagano survey. J Clin Endocrinol Metab 1999, 84: 561-566

25. Tazebay UH, Wapnir IL, Levy O, et al. The mammary gland iodide transporter is expressed during lactation and in breast cancer. Nat Med 2000, 6: 871-878

26. Stoddard FR, 2nd, Brooks AD, Eskin BA, Johannes GJ. Iodine alters gene expression in the MCF7 breast cancer cell line: evidence for an anti-estrogen effect of iodine. Int J Med Sci 2008, 5: 189-196

27. Bonacci R, Pinchera A, Fierabracci P, Gigliotti A, Grasso L, Giani C. Relevance of estrogen and progesterone receptors enzyme immunoassay in malignant, benign and surrounding normal thyroid tissue. J Endocrinol Invest 1996, 19: 159-164

28. Giani C, Campani D, De Negri F, et al. Interference of thyroperoxidase on immuno-cytochemical determination of steroid receptors in thyroid tissue. J Endocrinol Invest 1993, 16: 37-43

29. Manole D, Schildknecht B, Gosnell B, Adams E, Derwahl M. Estrogen promotes growth of human thyroid tumor cells by different molecular mechanisms. J Clin Endocrinol Metab 2001, 86: 1072-1077 
This is the peer reviewed version of the following article: Muller, I., Pinchera, A., Fiore, E. et al. J Endocrinol Invest (2011) 34: 349. https://doi.org/10.1007/BF03347458

The final publication is available at $\mathrm{https}$ ://link.springer.com/article/10.1007/BF03347458

30. Rajoria S, Suriano R, Shanmugam A, et al. Metastatic phenotype is regulated by estrogen in thyroid cells. Thyroid, 20: 33-41

31. Metso S, Auvinen A, Huhtala H, Salmi J, Oksala H, Jaatinen P. Increased cancer incidence after radioiodine treatment for hyperthyroidism. Cancer 2007, 109: 1972-1979

32. Holm LE, Hall P, Wiklund K, et al. Cancer risk after iodine-131 therapy for hyperthyroidism. J Natl Cancer Inst 1991, 83: 1072-1077

33. Hoffman DA, McConahey WM, Fraumeni JF, Jr., Kurland LT. Cancer incidence following treatment of hyperthyroidism. Int J Epidemiol 1982, 11: 218-224 
This is the peer reviewed version of the following article: Muller, I., Pinchera, A., Fiore, E. et al. J Endocrinol Invest (2011) 34: 349. https://doi.org/10.1007/BF03347458

The final publication is available at $\mathrm{https}$ ://link.springer.com/article/10.1007/BF03347458

Table 1: Previous and current treatments for thyroid diseases in the 38 patients with benign thyroid diseases (BTD) and breast cancer (BC).

\begin{tabular}{|c|c|c|c|c|c|c|}
\hline $\begin{array}{l}\text { Current } \\
\text { treatment }\end{array}$ & $\begin{array}{l}\text { Previous } \\
\text { treatment }\end{array}$ & GD & AT & $\mathrm{NG}$ & $\mathrm{NGAb+}$ & TOTAL \\
\hline \multirow[t]{2}{*}{ None } & 1 & 0 & 8 & 3 & 2 & 14 \\
\hline & Methimazole & 1 & 0 & 0 & 0 & 0 \\
\hline Methimazole & 1 & 0 & 0 & 2 & 0 & 2 \\
\hline \multirow{3}{*}{ L-Thyroxine } & 1 & 0 & 2 & $3 *$ & $1 *$ & 6 \\
\hline & $\mathrm{I}-131$ & 11 & 0 & 0 & 0 & 11 \\
\hline & Thyroidectomy & 1 & & 4 & 0 & 5 \\
\hline TOTAL & & 13 & 10 & 12 & 3 & 38 \\
\hline
\end{tabular}

* L-thyroxine treatment for nodular goiter 
This is the peer reviewed version of the following article: Muller, I., Pinchera, A., Fiore, E. et al. J Endocrinol Invest (2011) 34: 349. https://doi.org/10.1007/BF03347458

The final publication is available at $\mathrm{https}$ ://link.springer.com/article/10.1007/BF03347458

Table 2: Distribution of known breast cancer risk factors in patients with benign thyroid diseases (BTD) with $(\mathrm{BC}+)$ or without (BC-) breast malignancy.

\begin{tabular}{|c|c|c|c|}
\hline $\mathrm{BC}$ risk factors & $\mathrm{BC}+$ & BC- & $\mathrm{p}$ \\
\hline Family history of BC & $2 / 38(5,3 \%)$ & $14 / 584(2,4 \%)$ & ns \\
\hline Mean age of menarche (years \pm SD) & $12.6 \pm 1.8$ & $12.6 \pm 1.5$ & ns \\
\hline Mean age of menopause (years \pm SD) & $47.7 \pm 5.5$ & $48.6 \pm 4.6$ & ns \\
\hline Mean number of pregnancies $\left(n^{\circ} \pm S D\right)$ & $2.2 \pm 0.9$ & $2.2 \pm 1.1$ & ns \\
\hline Mean age at first pregnancy (years \pm SD) & $26.0 \pm 3.6$ & $27.2 \pm 5.1$ & ns \\
\hline Previous or concomitant estrogens therapies & $6 / 38(15.8 \%)$ & $194 / 584(33,2 \%)$ & ns $(*)$ \\
\hline Mean years of estrogens therapy (years \pm SD) & $4,3 \pm 7,0$ & $6,0 \pm 18,9$ years & ns \\
\hline Obesity & $16 / 38(42,1 \%)$ & $271 / 584(46,4 \%)$ & ns \\
\hline
\end{tabular}

* Not significant because of the small size of the patients' group 
This is the peer reviewed version of the following article: Muller, I., Pinchera, A., Fiore, E. et al. J Endocrinol Invest (2011) 34: 349. https://doi.org/10.1007/BF03347458

The final publication is available at https://link.springer.com/article/10.1007/BF03347458

Figure 1. Prevalence of breast cancer (BC) in patients with benign thyroid diseases (BTD: grey columns) and Italian female population (General Population: black columns).

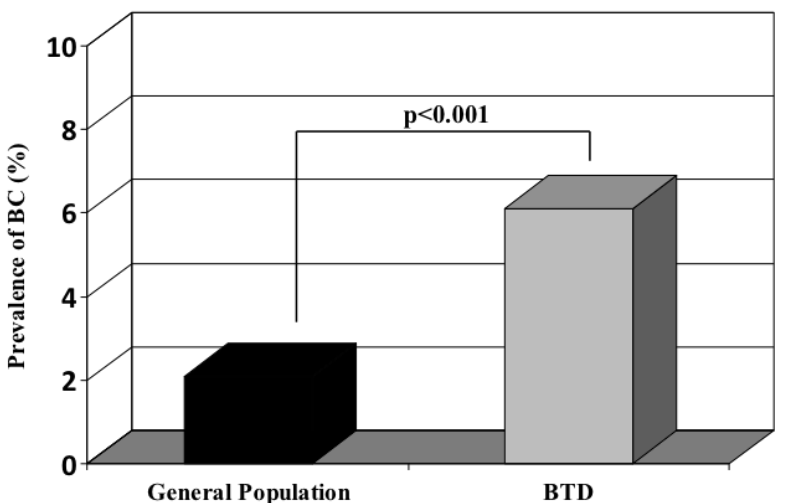

A

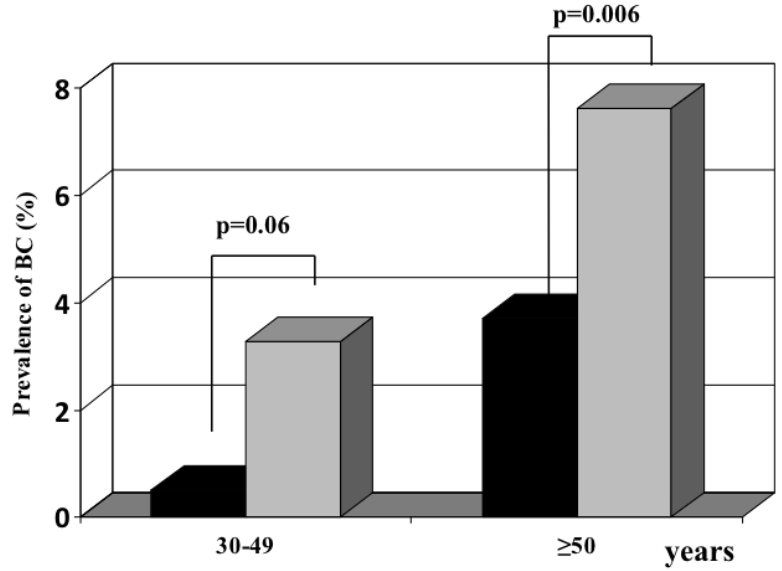

B

The prevalence of BC was significantly higher in patients with BTD than in Italian female population (panel A). When patients were divided according to the age of menopause (panel B), in females older than 49 years BC frequency in BTD was significantly higher than in age-matched population $(7.6 \%$ vs $3.3 \% ; p=0.006)$, while in female aged $30-49$ years BC frequency in BTD was higher but not statistically significant than in age-matched population $(3.7 \%$ vs $0.5 \%$; $\mathrm{p}=0.06)$ 